\section{BMJ Paediatrics Open}

\title{
Newborn biliary atresia screening with the stool colour card: a questionnaire survey of parents
}

To cite: Borgeat M, Korff S, Wildhaber BE. Newborn biliary atresia screening with the stool colour card: a questionnaire survey of parents. BMJ Paediatrics Open 2018;0:e000269. doi:10.1136/ bmjpo-2018-000269

Received 17 February 2018 Revised 17 April 2018 Accepted 19 April 2018
Check for updates

${ }^{1}$ Department of Pediatrics, University Hospitals of Geneva, Geneva, Switzerland

${ }^{2}$ Division of Paediatric Surgery, University Center of Paediatric Surgery of Western Switzerland, University Hospitals of Geneva, Geneva, Switzerland

Correspondence to Dr Barbara E Wildhaber; barbara.wildhaber@hcuge.ch

\section{ABSTRACT}

Purpose Biliary atresia can easily be screened using a stool colour card (SCC) and has shown to significantly reduce time to diagnosis, improving children's outcome. Despite the general approval of the clinical usefulness of the SCC, physicians remain reluctant: it might unnecessarily worry parents. This study aimed to analyse the parental reaction to this screening method and if it evokes parental stress.

Methods A semistructured questionnaire was sent to parents with one or more healthy child to inquire about reactions on receipt and use of the SCC.

Results 109/256 questionnaires were returned and evaluated (43\%). 107/107 parents considered the SCC as helpful, a simple screening method and easy to use (100\%). 26/43 were reassured when receiving the SCC $(60 \%), 2$ were worried $(5 \%)$ and 9 had no particular feelings (21\%). In 41/49, emotions experienced during its use were positive or neutral (84\%), and 3 were worried $(6 \%)$. In $41 / 50$, the discussion with the paediatrician about stool colour-linked pathologies was neutral (82\%), and 9 felt uneasy $(18 \%)$

Conclusion A vast majority of parents appreciate the SCC. It creates uneasiness in a minority of parents. Our results are encouraging and argue in favour of implementing the regular distribution of the SCC in antenatal, postnatal and newborn infant clinics.

\section{INTRODUCTION}

Biliary atresia is a rare pathology in newborns. ${ }^{1}$ It leads to the obstruction of the biliary tree, inducing neonatal cholestasis and biliary cirrhosis, leading to death in the first years of life if untreated. ${ }^{1}$ In Europe, biliary atresia affects between 1/14 000 and $1 / 20000$ live births; in Switzerland, the incidence is of $1 / 17800$ live births. ${ }^{2}$ The diagnosis is suspected in case of persistent jaundice, along with discoloured stools, darkyellow urine and hepatomegaly. ${ }^{3-5}$ The treatment of biliary atresia consists of the Kasai hepato-porto-enterostomy, aiming to restore bile flow, ${ }^{1}$ followed by liver transplantation if cirrhosis progresses. Biliary atresia is the most frequent indication for liver transplantations in children. ${ }^{6}$

\section{What is known about the subject?}

Screening with a stool colour card is a cost-effective and simple screening method for biliary atresia.

- Screening with a stool colour card helps to diagnose early biliary atresia.

- Concerns regarding parental anxiety are thought to be the reason why some Swiss physicians do not use the stool colour card.

\section{What this study hopes to add?}

A vast majority of parents appreciate the stool colour card for the screening of biliary atresia.

- It creates uneasiness in a minority of parents.

- Our results are encouraging and argue in favour of implementing the regular distribution of the stool colour card in antenatal, postnatal and newborn infant clinics.

The median age for the Kasai procedure in Switzerland is late 68 days. $^{2}$ Serinet et al observed, in a study of 695 patients who had undergone a Kasai procedure, that the earlier the operation was performed, the better was the survival rate of children with their native livers. ${ }^{7}$ Consequently, in order to avoid early liver transplantation, a neonatal screening is needed to allow for timely diagnosis of biliary atresia, so that the surgical treatment can be performed the earliest possible. Many screening programmes for biliary atresia have been proposed, such as measuring of serum bile acid, ${ }^{8}$ serum direct bilirubin, ${ }^{9}$ urinary sulfated bile acid, ${ }^{10}$ and faecal bilirubin and $\mathrm{fat}^{11}$; however, they have not been put into practice extensively. Yet, an easy method, which detects neonatal cholestasis in a simple way, and in particular biliary atresia, is to look at the baby's stool colour, pale in cases of cholestasis, that is, grey, cream or white, occasionally pigmented as a light caramel colour. ${ }^{12}$ Thus, a screening programme with a stool colour card (SCC), showing different normal and abnormal stool colours, to be 


\section{STOOL COLOR CARD}

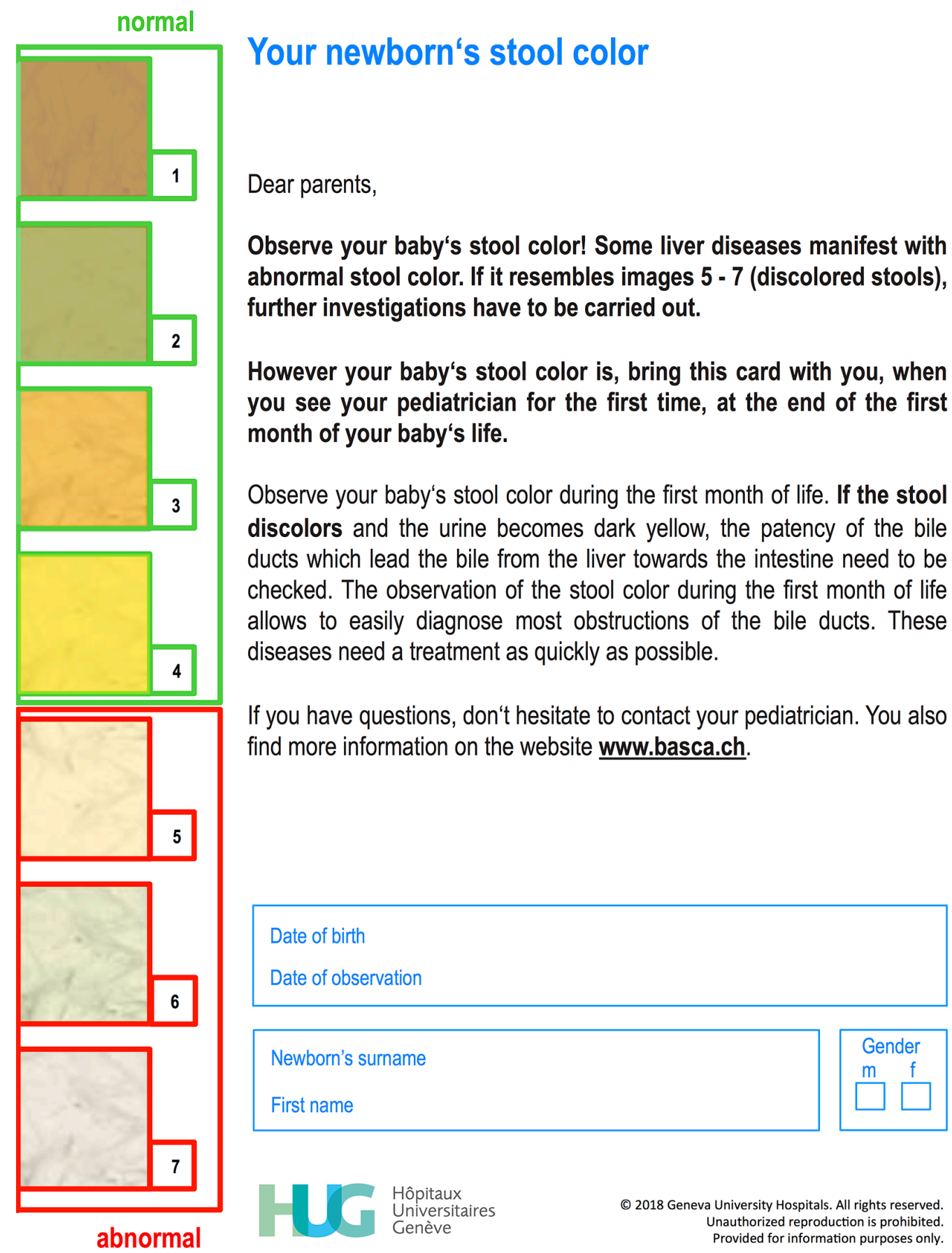

Figure 1 Swiss stool colour card, English version.

compared with the baby's stool, was first introduced in Japan in $1987^{13}$ and in 2002 in Taiwan. ${ }^{5}$ This has led to a significant reduction in late biliary atresia diagnoses, has allowed for significantly earlier Kasai operations, increased the jaundice clearance rate at 3 months after surgery, thus reducing the need for hazardous liver transplantation at a young age. ${ }^{14}$ The screening for biliary atresia or obstructive cholestasis with a SCC is increasingly used in Europe. In Germany, its use has become compulsory in 2016. In Switzerland, the card has been available for optional distribution since $2009 .{ }^{15}$ The Swiss SCC is an A5 formatted hard paper card and shows four normal and three pathological babies' stool colours (figure 1, see also www.basca.ch). It is handed out at birth or at 4 weeks of life at the first appointment with the paediatrician. If an abnormal stool colour is observed, the paediatrician is thought to either immediately contact a paediatric gastroenterologist, or the Swiss Pediatric Liver Center in Geneva, for further advice. The parents also have the possibility to directly reach the Geneva Centre 


\section{Box 1 Questionnaire}

- How many children do you have? How old are they?

Do you know a baby's normal stool colour?

- Do you know the stool colour card (card which shows the normal and abnormal stool colours)?

Do you know the disease called 'biliary atresia'?

Did you receive a stool colour card for your baby?

- If yes: did you use the card?

- If no: why not?

- If you received the stool colour card:

- Who did it give to you?

- When did you receive it?

- How did you react when you received it?

- At what moment do you think parents should receive the stool colour card?

Do you think that the stool colour card is easy to use?

Are the explications on the card clear?

Does the website www.basca.ch give clear information?

- Are the stool colours on the card accurate?

Did you find it difficult to choose a colour?

- How did you react when your paediatrician discussed with you diseases related to your baby's stool colour?

- How did you react when you used the stool colour card?

- Did you have to ask your paediatrician questions (or via the website www.basca.ch)?

- To what degree do you agree with the following statements?

- I think the stool colour card is useful.

- I think the stool colour card is easy to use.

- I think the stool colour card not necessary.

- I think that the stool colour card can reassure parents.

- I think that the stool colour card is an easy tool to discover liver disease in newborns.

- I think the stool colour card should be introduced in the baby's health booklet.

- I think the stool colour card should be introduced in the baby's vaccination record.

- What is your general meaning about the stool colour card?

Questionnaire used in this study. All but the last one were questions with a list of answers to choose from. The last question allowed for free text.

by email (link on the website). Since Switzerland is a small country, this process is feasible and prevents time loss in the process of the so much sought early diagnosis of biliary atresia.

Paediatricians' reactions to the introduction of the SCC are substantial. Despite the general approval of the usefulness of the SCC, physicians remain reluctant to the definitive and nationwide implementation of this screening method. Some healthcare providers consider that the distribution of the SCC might unnecessarily worry parents and add unnecessary consultations. The aim of this study was to analyse and clarify the parental reaction to the SCC in Switzerland.

\section{Patients and methods}

A semistructured questionnaire was designed for parents to assess the SCC's handiness of use, and what feelings its receipt and use triggered (box 1). Between 2013 and 2016, 256 questionnaires were distributed to parents with at least one child in three different parts of Switzerland (Italian, German and French-speaking). The distributed envelopes contained an introduction letter addressed to parents, the questionnaire, the SCC and a stamped, addressed envelope to return the questionnaire. All documents were written in the three languages.

The reported percentages were calculated according to the number of answers obtained per question. No statistics were performed, the results being simply descriptive.

\section{RESULTS}

\section{Descriptive results}

A total of 109/256 (43\%) questionnaires were returned and evaluated. There was a difference between the language regions from where the questionnaires were returned: the participants responding from Italian-speaking Switzerland returned 48/50 (96\%) of questionnaires, from the German-speaking Switzerland 20/100 (20\%) were returned and from the Frenchspeaking 41/106 (39\%). Twenty-three parents (21\%) used the card in 'real-time', that is, with their just born baby; the remainders used the card after their stay at the maternity clinic. Forty parents $(37 \%)$ used the card with their first baby. Most parents wished to receive the SCC at the maternity clinic $(85 / 106,80 \%)$; the remainders preferred to receive it after having left the clinic, either by their paediatrician or their midwife. Most parents $(98 / 100,98 \%)$ had never heard about biliary atresia before receiving the SCC.

\section{Parents' reaction to the SCC}

As to the SCG's user-friendliness, $100 \%(107 / 107)$ of parents found it either 'very' easy to use $(69 / 107,64 \%$ ) or 'quite' easy to use $(38 / 107,36 \%)$. The written explanations on the SCC regarding the screening were considered to be clear $(105 / 108,97 \%)$. The majority of parents needed no further explanations from their paediatrician $(90 / 93,97 \%)$. The colours on the card were considered appropriate in $98 \%(103 / 105)$. The majority of parents had no difficulty in identifying the matching colour $(93 / 103,90 \%)$

When receiving the SCC, $60 \%(26 / 43)$ of parents were reassured, 21\% (9/43) had no particular feelings and 5\% $(2 / 43)$ were worried (figure 2$)$.

Emotions experienced during the use of the SCC were in $84 \%(41 / 49)$ positive or neutral; $6 \%(3 / 49)$ of parents were worried when using the SCC (figure 2). For both questions (receipt and use), multiple answers were possible. When analysing the subgroup of parents using the SCC with their very newborn in the maternity clinic, they were clearly not worried at all $(0 / 19$ worried $)$, and $100 \%(19 / 19)$ were reassured, surprised or indifferent when using it.

The conversation later on with the paediatrician about pathologies linked to the stool colour was not a source of concern in $82 \%(41 / 50)$ of parents; $18 \%(9 / 50)$ 


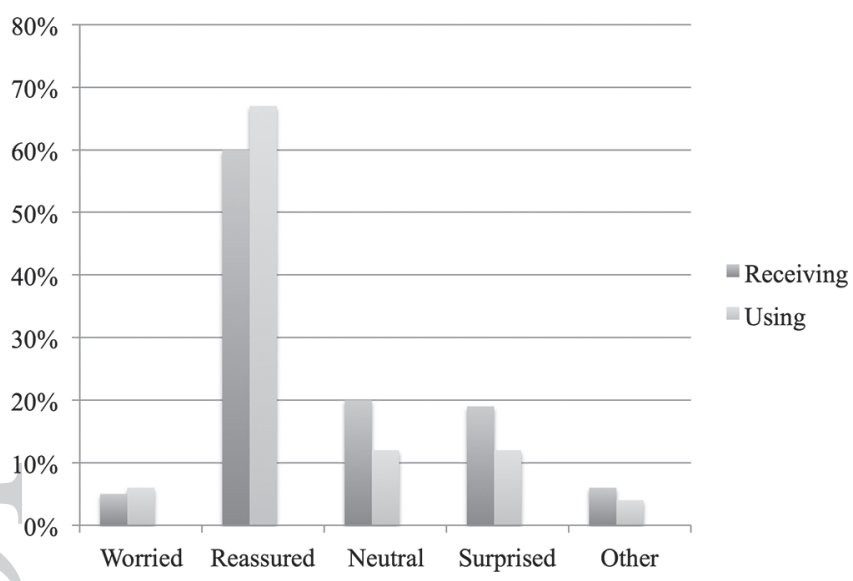

Figure 2 Parent's reaction when receiving and using the stool colour card. Parents were mostly reassured or had neutral feelings.

expressed that they felt some degree of uneasiness during this conversation (figure 3).

The answers to the last question of the questionnaire, requiring comments, are not reported in detail, but in general commentaries again were positive.

\section{DISCUSSION}

It is now established and generally acknowledged that the SCC for newborns is a sensitive and specific screening method for biliary atresia and consequently improves prognosis of those patients by reducing the age when the Kasai procedure is performed. ${ }^{515}$ The positive clinical effects of the SCC has repeatedly been demonstrated in Taiwan from the beginning of the years $2000 .{ }^{5}{ }^{14}$ It is now also widely accepted that the SCC screening increases parents' and physicians' awareness of biliary atresia and thus is associated with a decrease of late referrals of affected babies. ${ }^{14}$ After the strong success of the SCC in Taiwan, many other countries have developed screening and biliary-atresia-awareness-raising programmes. In France, a video campaign was initiated in 2014 (http:// www.youtube.com/watch?v=XsSXmR4u2uM).

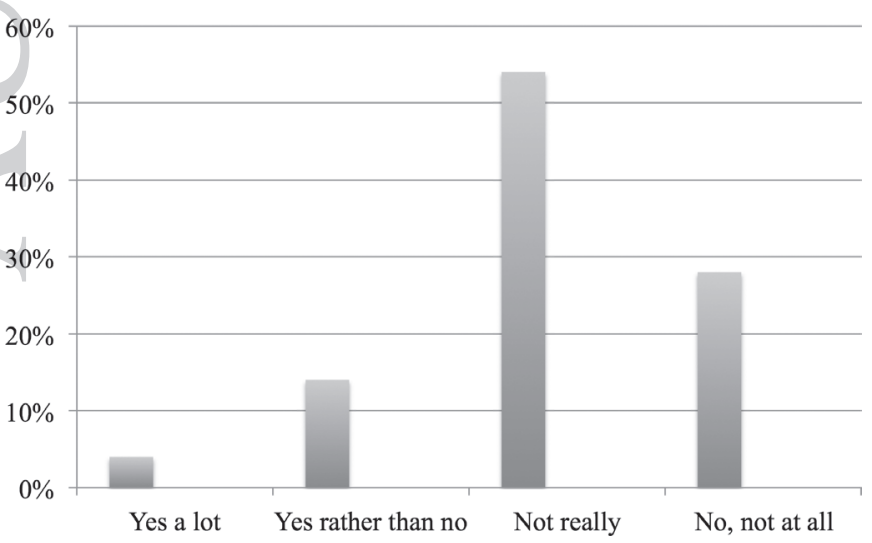

Figure 3 Parent's reaction during the discussion with the paediatrician about diseases related to the stool colour. Little concerns were observed.
In Switzerland, the SCC has been available since October 2009 and can be ordered by physicians, maternity clinics and midwives via a website designed for this purpose (www.basca.ch). Thus, the Swiss SCC is either distributed right after birth, 1 or 2 weeks later, or at the baby's age of 1 month when it is seen for the first time by his paediatrician. In our survey, parents felt that the best moment to receive the SCC is at the maternity clinic and that it should be inserted into the children's health booklet. Indeed, if the SCC is only distributed at the first appointment when the baby is 4 weeks old, this may lead to delayed diagnosis: a crucial indicator for the diagnosis of biliary atresia is the typical shift of the stool colour from dark yellow to grey pale over the first weeks of life. We must aim to assure that maternity clinics deliver the SCC right after childbirth and have the parents repeatedly observe their newborns' stool colour. Consequently, the paediatrician will analyse and address, and not introduce, the SCC at the baby's first appointment.

As for the handiness of the SCC, most parents considered the stool colours on the card as appropriate and had no difficulties in choosing the right shade. However, our experience with parents with biliary atresia babies tells us that in cases of pale stools, that is, 'biliary atresia-stools', it might be difficult to choose the right colour due to the staining of the baby's stools by the dark-yellow urine. The paediatrician must be aware of this and check the baby's stool himself.

An additional uneasiness of paediatricians is the possible time consumption it may create, that the analysis and discussion of the SCC may require (too much) time. Our study refutes this assumption: most of the parents did not need further explanations about the card and its content during the time spent with their paediatrician. We do believe that the paediatrician, at the first appointment with his new patient, in any case, is thought to ask about the stool and urine colour; the expenditure of time thus remains the same, with our without the SCC, or, we dare say, might be even less, since the parents are prepared to the questions after having used the SCC.

One of the chief objectives of this survey was to evaluate the degree of parental concern when receiving and using the SCC. The vast majority of parents were, on receipt of the card, reassured by or indifferent to the SCC. The individual use of the SCC was, in general, not a negative or worrisome experience. The conversation with the paediatrician pathologies linked to the newborn's stool colour generally did not worry them. But indeed, some parents expressed concerns either when receiving $(5 \%)$ or when using $(6 \%)$ the SCC. Only during the conversation later on with the paediatrician about pathologies linked to the stool colour more parents, $18 \%$, expressed that they felt some degree of uneasiness during this conversation (4\% 'yes a lot', $14 \%$ 'yes rather than no'). It seems to us that this is a rather 'normal' reaction and not clearly due to the SCC, since parents naturally often feel uncomfortable during a discussion about possible pathologies linked to their baby, mirrored by the $14 \%$. Indeed, $4 \%$ 
were clearly anxious, which is in line with the numbers reported after receiving of the SCC and during its use. The $18 \%$ of uneasiness are also in agreement with the generally reported postnatal anxiety, which is indicated to be common: the literature states that up to $18 \%$ of mothers experience some degree of anxiety in the first months after birth, and even more so if the newborn is a first-born. ${ }^{16-18}$ Seen in this context, our results are expected and rather reassuring. One of the major factors creating anxiety in screening processes is the time period awaiting results and/or before seeing a professional to be counselled and reassured. ${ }^{19}$ Importantly and in any case of screening, professional backup by midwives or paediatricians must be easily accessible. In this particular screening, parents can also be encouraged to use the electronic contact noted on the SCC, which allows for direct and ready exchange with the coordinators of the Swiss screening centre. Further, it is of utmost importance to address possible concerns before they appear, and the SCC must be introduced with appropriate, concise explanations.

This work has some weaknesses. It is a very small study, with a little response rate. Thus, we consider it as of preliminary—but path breaking-character; the enquiry might gain in impact if repeated on a larger scale, for example using telephone consultations. Further, there were significant differences in the return rate of the questionnaires depending on the language region. Since we omitted to ask for personal details of the responders, we are unable to say if this is due to the cultural background of the parents or due to the different introduction of the questionnaire by the local paediatrician, even more so since Switzerland is a very multicultural country in every language region.

In conclusion, the vast majority of parents judged the SCC as useful, easy to use and being a simple screening method. Parents' concerns when receiving or using the SCG were minor. The SCG was not adding unnecessary consultations, and the card-related discussion with the paediatrician was not a source of anxiety. Our results are encouraging and argue in favour of implementing the regular distribution of the SCC in antenatal, postnatal and newborn infant clinics in Switzerland and beyond.

Acknowledgements Our sincere thanks go to Nicole Pellaud, president of the Swiss group for social and preventive paediatricians, for her assistance in preparing the questionnaire, as well as to the paediatricians Dr Rossetti, Dr HaldiBrändle, Dr Ziegler, Dr Reinhardt, Dr Benador, Dr Salamoni and Dr Lironi for their help with the distribution of the questionnaires. The authors thank Nastassia Guanziroli, Nicolas Broc, Linda Menchi and Cornelia Orth for their support in the translation of the numerous documents. The Swiss SCC project is supported by the Centre de Recherche Clinique (CRC) and the paediatric research platform of the Geneva University Hospitals, as well as by the Association Enfance et Maladies Orphelines (AEM0), the Wyeth Foundation, Novartis Foundation for medical research and Astellas.
Contributors MB: concept/design, data collection and analysis/interpretation, drafting article. SK: data interpretation, critical revision of article. BEW: concept/ design, data analysis/interpretation, critical revision of article.

Funding The authors have not declared a specific grant for this research from any funding agency in the public, commercial or not-for-profit sectors.

Competing interests None declared.

Ethics approval Ethical approval for this study was obtained from the local Ethics Committee (CER 07-245).

Provenance and peer review Not commissioned; externally peer reviewed.

Open Access This is an Open Access article distributed in accordance with the Creative Commons Attribution Non Commercial (CC BY-NC 4.0) license, which permits others to distribute, remix, adapt, build upon this work non-commercially, and license their derivative works on different terms, provided the original work is properly cited and the use is non-commercial. See: http://creativecommons.org/ licenses/by-nc/4.0/

(C) Article author(s) (or their employer(s) unless otherwise stated in the text of the article) 2018. All rights reserved. No commercial use is permitted unless otherwise expressly granted.

\section{REFERENCES}

1. Wildhaber BE. Biliary atresia: 50 years after the first Kasai. ISRN Surg 2012;2012:1.15.

2. Wildhaber BE, Majno P, Mayr J, et al. Biliary atresia: Swiss national study, 1994-2004. J Pediatr Gastroenterol Nutr 2008;46:299-307.

3. Alagille D. Extrahepatic biliary atresia. Hepatology 1984;4:7S-10.

4. Chang MH. Screening for biliary atresia. Chang Gung Med $J$ 2006;29:231.

5. Chang MH, Chen SM, et al. Screening for biliary atresia by infant stool colour card in Taiwan. Paediatrics 2006;117:1147-54.

6. Sokol RJ, Shepherd RW, Superina R, et al. Screening and outcomes in biliary atresia: summary of a National Institutes of Health workshop. Hepatology 2007;46:566-81.

7. Serinet MO, Wildhaber BE, Broué $P$, et al. Impact of age at Kasai operation on its results in late childhood and adolescence: a rational basis for biliary atresia screening. Pediatrics 2009;123:1280-6.

8. Mushtaq I, Logan S, Morris M, et al. Screening of newborn infants for cholestatic hepatobiliary disease with tandem mass spectrometry Commentary: What is tandem mass spectrometry? BMJ 1999;319:471-7.

9. Mowat AP, Davidson LL, Dick MC. Earlier identification of biliary atresia and hepatobiliary disease: selective screening in the third week of life. Arch Dis Child 1995;72:90.2.

10. Matsui A, Kasano Y, Yamauchi Y, et al. Direct enzymatic assay of urinary sulfated bile acids to replace serum bilirubin testing for selective screening of neonatal cholestasis. J Pediatr 1996;129:306-8.

11. Akiyama T, Yamauchi Y. Use of near infrared reflectance spectroscopy in the screening for biliary atresia. $J$ Pediatr Surg 1994;29:645-7.

12. Lai MW, Chang MH, Hsu SC, et al. Differential diagnosis of extrahepatic biliary atresia from neonatal hepatitis: a prospective study. J Pediatr Gastroenterol Nutr 1994;18:121-7.

13. Matsui A, Ishikawa T. Identification of infants with biliary atresia in Japan. Lancet 1994;343:925.

14. Tseng JJ, Lai MS, Lin MC, et al. Stool color card screening for biliary atresia. Pediatrics 2011;128:e1209-e1215.

15. Wildhaber BE. Screening for biliary atresia: Swiss stool color card. Hepatology 2011;54:368.

16. Fairbrother $\mathrm{N}$, Janssen $\mathrm{P}$, Antony MM, et al. Perinatal anxiety disorder prevalence and incidence. $J$ Affect Disord 2016;200:148-55.

17. Hayashida K, Nakatsuka M. Promoting factors of physical and mental development in early infancy: a comparison of preterm delivery/low birth weight infants and term infants. Environ Health Prev Med 2014;19:160-71.

18. Seymour M, Giallo R, Cooklin A, et al. Maternal anxiety, risk factors and parenting in the first post-natal year. Child Care Health Dev 2015;41:314-23.

19. Ulph F, Cullinan T, Qureshi N, et al. Parents' responses to receiving sickle cell or cystic fibrosis carrier results for their child following newborn screening. Eur J Hum Genet 2015;23:459-65. 